Fanum

Sociológico

\section{Forum Sociológico}

Série II

27 | 2015

Mobilidade científica \& imigração qualificada

\title{
Mobilidade Científica: Do ponto de vista de uma mexicana em movimiento
}

María del Carmen Castillo Cisneros

\section{OpenEdition}

1 Journals

Edição electrónica

URL: https://journals.openedition.org/sociologico/1311

DOI: 10.4000/sociologico.1311

ISSN: 2182-7427

Editora

CICS.NOVA - Centro Interdisciplinar de Ciências Sociais da Universidade Nova de Lisboa

Edição impressa

Data de publição: 21 dezembro 2015

Paginação: $75-77$

ISSN: 0872-8380

\section{Refêrencia eletrónica}

María del Carmen Castillo Cisneros, «Mobilidade Científica: Do ponto de vista de uma mexicana em movimiento», Forum Sociológico [Online], 27 | 2015, posto online no dia 27 maio 2016, consultado o 31 março 2022. URL: http://journals.openedition.org/sociologico/1311 ; DOI: https://doi.org/10.4000/ sociologico. 1311 


\title{
MOBILIDADE CIENTÍFICA: DO PONTO DE VISTA DE UMA MEXICANA EM MOVIMIENTO
}

\author{
María del Carmen Castillo Cisneros \\ Departamento de Antropología Social, Instituto Nacional de Antropología e Historia, Centro INAH-Oaxaca
}

Soy antropóloga social, nacida en la ciudad de Puebla, México. Por parte de mi madre soy la tercera generación nacida en dicha ciudad y por parte de mi padre parece ser que la quinta si no es que más. Por lo visto a mi familia le gusta su lugar de origen y permanecer en él. Me crié ahí, estudié quince años en el mismo colegio desde el preescolar hasta la preparatoria y luego estudié Antropología Cultural en la Universidad de las Américas Puebla (UDLAP). Todo en la misma ciudad de provincia y todo iba por ese camino de permanencia, hasta que el trabajo etnográfico se cruzó en mi vida y mi brújula viró hacia Oaxaca, el estado vecino del sur.

En un Congreso de la Sociedad Mexicana de Antropología (SMA), la entonces jefa de departamento de mi facultad, la Dra. Gabriela Uruñuela me presentó a la Dra. Alicia Barabas y al Dr. Miguel Bartolomé, una pareja de antropólogos argentinos, profesores-investigadores del Instituto Nacional de Antropología e Historia (INAH) adscritos al Centro Regional Oaxaca. Me dijo: "ellos hacen etnografía de verdad" y desde ese día me invitaron a colaborar en un proyecto que coordinaban a nivel nacional. Envié mi curriculum a la Dra. Uruñuela, quien quería dar el visto bueno antes de enviarlo y, sin miramientos, borró casi todo, dejando a lo mucho, mi nombre y dos o tres actividades. Viendo mi ingenuidad me explicó que si no había participado con ponencias en los congresos o seminarios, su validez era nula.

Me percaté entonces que había que participar, hacer conexiones, conocer más gente, moverse. Era 2001 cuando me fui a trabajar a Oaxaca como ayudante de investigación, sin paga alguna, solo recibía viáticos con los cuales me sentía triunfante. Comenzó mi movilidad, no por un erasmus en el extranjero, ni viajando en interrail para conocer toda Europa o como au pair en Estados Unidos o Francia cuidando niños (todo ello también hubiera estado bien sin duda). Mi movilidad fue al interior de mi propio país, en uno solo de sus estados, recorriendo casi todas las cabeceras de distrito que conforman Oaxaca y visitando las ocho regiones en que se divide. Quedé maravillada, no solamente por el hecho de moverme y conocer diferentes pueblos sino por la diversidad cultural de la que fui testigo y que me rebasó. Desde entonces, nunca más me fue ajena. De paso, me fui formando como etnógrafa, en el terreno mismo, fuera de las aulas, siguiendo el legado de Bartolomé (2003:216) de que "las teorías pasan pero las etnografías permanecen".

Un año después me mudé a un pueblo cerca de la costa oaxaqueña, para hacer el trabajo de campo de lo que conformaría mi tesis de licenciatura, una etnografía sobre el pueblo tacuate. Este pueblo, es uno de los 16 pueblos indígenas originarios del estado de Oaxaca. Viví en la comunidad de Santa María Zacatepec por espacio de un año, experimentando de primera mano que, "la etnografía es una tradición porque envuelve a la persona entera. Salir, hablar con la gente en un contexto cara a cara implica ser humano de una manera holística y la intersubjetividad es algo que solo puede pasar a los humanos en plenitud". (Pina-Cabral, 2011: 391).

Se trataba de una movilidad con mis connacionales; mestizos e indígenas, mexicanos igual que yo, pero cuya realidad era tan diferente a la mía como si me hubiera insertado en un pueblo de Islandia. Hoy veo que a partir de experiencias como esta comencé a ver lo diverso con otros ojos y a tratar de comprender su existencia aún con mis propias limitantes.

Luego me mudé a la ciudad de Oaxaca, lugar donde he residido los últimos años. Recorriendo, conociendo, haciendo trabajo de campo y enseñando en diferentes partes del estado. Hace diez años fui a mi primer ICA (International Congress of Anthropology) en Sevilla donde hablé de migración y cambios en el sistema normativo interno de la comunidad de San Francisco Cajonos en la Sierra Norte de Oaxaca. A ese congreso le han seguido muchos de carácter nacional e internacional, así como participaciones en seminarios, talleres, conferencias y estancias académicas en universidades de Europa. De hecho, regresé a Sevilla en Otoño de 2014 como parte de los intercambios académicos del Proyecto Multilevel governance of cultural Diversity in a comparative perspective: EU-Latin America financiado por AMC (Actions Marie Curie) de la Comisión Europea del cual formo parte y que este año me tiene colaborando académicamente en una estancia con la Universidad de Lisboa. 
Entre 2008 y 2014 estudié la maestría en Etnografía y Antropología y el Doctorado en Estudios avanzados en Antropología Social en la Universidad de Barcelona. Me moví otra vez, ahora si fuera de mi país y por un tiempo largo. Fue un camino muy interesante y de muchos contrastes en aprendizaje. Idas y vueltas para hacer trabajo de campo en México me permitían mantener un pie en Europa y otro en mi país de origen. Esto debido a mi interés por continuar haciendo antropología en México pero haciendo estudios en Europa y también por aquello de lo que llaman "amores en tiempos de Ryanair" que atravesamos los que alguna vez hemos tenido el status de LAT (living apart together) por algunos años. Al final, me las ingenié para estar aquí y allá, haciéndome la vida más difícil o no, siendo extranjera con todo lo que ello implica (visados, permisos de residencia, trámites, gestiones, pago de tasas) pero participando en un grupo de investigación dentro de la Universidad de Barcelona que me ofreció contactos y experiencias de jornadas académicas con antropólogos de diferentes Universidades. Al mismo tiempo mantuve lazos con investigadores del Centro INAH de Oaxaca, del que nunca me desligué completamente. Vale la pena mencionar que fui becada por el CONACYT, (Consejo Nacional de Ciencia y Tecnología) y mi situación en comparación con otros compañeros tanto europeos como de otros lugares de América Latina fue bastante privilegiada.

Mientras hacía el doctorado me invitaron a participar en un proyecto educativo en la Sierra Norte de Oaxaca en una comunidad mixe. Se trataba de la apertura de una Universidad en un contexto comunitario. Así que me incorporé como profesora de la materia Métodos Etnográficos dentro de la Licenciatura en Educación Media Superior Comunitaria con un perfil intercultural. Mi movilidad científica, era a una comunidad, pero ahora con el papel de maestra, un trabajo (muy poco remunerado) y con muchas carencias. Los primeros meses no tuvimos pizarrones, así que improvisamos con las ventanas de las aulas, teníamos el ímpetu de comenzar con el proyecto.

Fue así que durante un año, mis movimientos académicos se repartieron entre la ciudad de Oaxaca, la comunidad de Alotepec y Barcelona. Teniendo lo mejor y también lo no tan bueno que existe detrás de todo lugar. Cada uno son mundos con sus propios códigos culturales, múltiples lecturas y diversidades al interior.

Lo cierto es que en la movilidad uno se adapta, conoce, interactúa y se divierte pero también vives momentos de desesperación, incertidumbre, añoranza. Lo que quiero decir aquí, es que para mí han sido igualmente satisfactorios y contrastantes los desplazamientos a culturas ajenas a la mía y que en todos los casos los considero experiencias académicas que van aportando elementos muy valiosos en mi formación profesional. Antes de terminar el doctorado, obtuve una plaza de investigación científica en el INAH y por ello es que finqué mi residencia en México, sin que ello signifique el termino de movilidades, por el contrario, los proyectos para intercambiar experiencias espero crezcan y se consoliden en un futuro cercano.

¿Qué me ha dado Europa?

Evidentemente aprendizajes de múltiple índole, tanto académicos como personales; de arte a través de la visitas a espacios culturales, museos, exposiciones, etc. También conocí otras maneras de utilizar y habitar los espacios públicos, de relacionarse y de entender las ciudades. Me enfrenté a otro tipo de academia, otras burocracias, otros códigos. Conocí amigos que se volvieron mi familia. Pero también vivir fuera de mi país de origen me mostró que ser extranjero cansa, que existen desventajas, que al final, eres de otro lugar. $Y$ no necesariamente se tiene que vivir en carne propia para saberlo. Como siempre he dicho, en términos de inequidad, Europa está muy cerca de México, pero México está muy lejos de Europa. Esto es una verdad para América en general. Los americanos ( $y$ con ello me refiero a los habitantes de todo el continente), de alguna u otra manera tenemos referencias de Europa, información, conocimiento, dicho en otras palabras, en promedio, nos mantenemos bastante al tanto. En dirección contraria, uno se sorprende al ver lo poco que se sabe de un basto y pluricultural continente que está cruzando el charco.

¿Qué me ha dado vivir en comunidades indígenas de México?

Muchísimo. Me ha mostrado las varias caras del país donde nací y con ello las infinitas maneras de estar en el mundo y concebirlo. También me ha dado conocimiento de diversas temáticas. Si bien no me he formado académicamente en las comunidades, he recibido de sus habitantes lecciones, conceptos y también reclamos sobre lo que "los antropólogos" decimos, creemos y reproducimos equívocamente o sin cuestionar y ello me parece es una gran aportación en términos de mi disciplina y en el campo del diálogo intercultural. Asimismo, he tenido acercamiento a otras teorías de conocimiento igualmente fundadas, veraces y sustentadas como las de Occidente y que no han sido reconocidas como tales. Comidas, costumbres, intercambios, amigos, familia. Aprendí también a ser "el otro", a que por más convivencia y empatía que pueda llegar a tener con los habitantes de un pueblo también existe un sentimiento de no pertenencia; distinto al que implica no compartir nacionalidad, pero siempre presente.

Es así que para mí, los frutos de ambas movilidades son igualmente ricos

Al ser extranjera en otras latitudes, entendí mejor la migración como fenómeno social y dentro de ella, observé como la población indígena de mi 
país es tratada como una ciudadanía de segunda categoría al igual que muchos migrantes son tratados en el extranjero. Solo que en nuestro caso, dicha población, que además ha querido ser invisibilizada, se vuelven extranjeros en su propio país (en términos de desigualdad, exclusión, clasismo).

Muchos más detalles podría enumerar, como las diferencias entre ser un académico extranjero, un académico indígena o un académico "asecas" solo porque ejerces en tu país de origen siendo mestizo (en el caso de México) y eso no implica añadir etiquetas extras. Las clasificaciones, las categorías, las exclusiones sociales, se hacen evidentes en el contexto de movilidad y los científicos no escapamos de ello.

Sin embargo, como antropóloga social creo que la movilidad es una fortaleza y en mi caso tanto la que he realizado al interior de mi país como al extranjero me llevan a pensar en el ejercicio de "una etnicidad" y cómo esta, es un motor político que forma parte de nuestra realidad como seres sociales. Ser extranjero significa muchas cosas, ya el término es multivocálico. Entre otras, significa vivir en una constante explicación. Dar cuenta de tu país repetidamente, como si de él, lo supieras todo y de todo fueras un experto. Es fácil perderte y viniendo de un país como México que da tanto de qué hablar, el asunto se agudiza. Ser extranjero, exige la mayoría de las veces un posicionamiento. Y no solamente cuando de partidos de futbol se trata, sino de acontecimientos sociales, movimientos políticos, sistemas económicos, decisiones de gobierno.

¿Cómo abordar el \#yosoy132, Ayotzinapa, la tragedia de la guardería $A B C$, el crimen organizado, el narcotráfico o hablar de la justicia en tiempos de la normalización de la violencia con mis colegas, alumnos o amigos de otros países? O ¿cómo explicar el México desigual, los estereotipos sociales, los efectos del colonialismo, el clasismo y muchos más ismos que son parte de nuestro cotidiano?

Esto me lleva a pensar que la movilidad nos hace ser móviles de muchas otras cosas y, no debemos olvidar que nuestro discurso puede tener un peso político. La movilidad científica implica por tanto, una responsabilidad político-social que debemos asumir.

Celebro la movilidad en todas direcciones, hacia el sobrevalorado "ideal mundo occidental", que reproduce el "quédate por ahí ", "ahí todo es mejor" y la movilidad al interior de la realidad y diversidad de nuestros propios países (un abanico que va más allá de los pueblos indígenas en toda América), que no por ser diferente, no merece la pena.

La movilidad es parte de nuestra condición como humanos y parafraseando a Latour (2007) es evidente que "nunca fuimos modernos", nos movemos desde que existimos como especie. Independientemente de si una migración es por estudios, laboral, por amor o porque no hay de otra... todos nos movemos. Algunas movilidades nos colocan en situaciones privilegiadas y otras en situaciones de precariedad; esto indiscutiblemente es digno de atención. Como científicos sociales nos corresponde avocarnos al conocimiento de su praxis, causas y efectos.

Dicen por ahí, que hablando se entiende la gente. Soy partidaria del diálogo intercultural y creo, tal vez ingenuamente, que algún día, existirá uno en igualdad de condiciones, sean cuales sean las culturas que se pongan en ello. Pero, si por el momento con el habla no lo hemos logrado, espero que moviéndonos (con todo lo que ello implica) logremos tolerarnos y comprendernos no solamente como paisanos, compatriotas o colegas; sino como parte de lo que siempre compartiremos: la condición de ser humanos.

\section{Referencias bibliográficas}

BARTOLOMÉ, M. (2003), "En defensa de la etnografía. El papel contemporáneo de la investigación intercultural", Revista de Antropología Social, 12, pp. $199-222$.

LATOUR, B. (2007), Nunca fuimos modernos. Ensayo de antropología simétrica, Argentina, Siglo Veintiuno editores.

PINA-CABRAL, J. (2011), "Ethnography as tradition in Africa", Etnográfica, 15 (2), pp. 379-407.

Recebido a 30/10/2015. Aceite para publicação a 30/11/2015.

María del Carmen Castillo Cisneros (carmen_castillo@inah.gob.mx). Departamento de Antropología Social, Instituto Nacional de Antropología e Historia, Centro INAH-Oaxaca. Pino Suárez 715 Centro, 68000 Oaxaca, Oaxaca, Mexico. 